\title{
IDENTIFICACIÓN DE BACTERIAS ENDÓFITAS RESISTENTES A PLOMO, AISLADAS DE PLANTAS DE ARROZ ${ }^{1}$
}

\author{
Alexander Pérez-Cordero², Zafiro Barraza-Roman², Dalila Martínez-Pacheco²
}

\section{RESUMEN}

Identificación de bacterias endófitas resistentes a plomo, aisladas de plantas de arroz. El objetivo de este estudio fue evaluar in vitro la resistencia de bacterias endófitas a diferentes concentraciones de plomo. El muestreo se realizó en el primer semestre de 2013, durante el cual se colectaron muestras de tejidos de variedades comerciales de arroz en etapa de macollamiento cultivadas en el municipio de Montería, Córdoba, Colombia. Cada tejido fue sometido a proceso de desinfección superficial. Se aislaron bacterias endófitas en medio de cultivo agar $\mathrm{R}_{2} \mathrm{~A}$; a partir de cada tejido se determinó la densidad poblacional (UFC/g de tejido) por el método de conteo sobre la superficie de medio $R_{2} A$; la separación de morfotipos se realizó mediante la forma, color, tamaño y apariencia. Un total de 168 morfotipos fueron aislados de raíz, macolla y hoja de diferentes variedades comerciales de arroz. La prueba de resistencia a plomo se realizó in vitro, para esto se prepararon suspensiones de bacterias en fase $\log$, se inocularon en medio mínimo con cinco concentraciones de plomo en forma de $\mathrm{Pb}\left(\mathrm{NO}_{3}\right)_{2}$. El ensayo se llevó a incubación con agitación por $150 \mathrm{rpm}$, a $32{ }^{\circ} \mathrm{C}$ por cinco días. Cada hora después de iniciado el ensayo se realizó lectura de la turbidimetría a $600 \mathrm{~nm}$. Las bacterias mostraron la capacidad de crecer a concentraciones de $100 \%$ de $\mathrm{Pb}$ en forma $\mathrm{Pb}\left(\mathrm{NO}_{3}\right)_{2}$. La identificación con el kit API20E confirmó la presencia de Burkholderia cepacia y Pseudomonas putida, las cuales mostraron resistencia a diferentes concentraciones de plomo.

Palabras clave: Oryza sativa, microorganismos endófitos, fitoremediación.

\begin{abstract}
Identification of lead- resistant endophytic bacteria isolated from rice. The objective of this study was to evaluate in vitro the endophytic bacteria resistance to different lead concentrations. The sampling was undertaken in the first half of 2013, when tissue samples of commercial varieties of rice at tillering stage were collected in Montería, Cordoba, Colombia. Each tissue was subjected to surface cleaning. Endophytic bacteria in agar $\mathrm{R}_{2} \mathrm{~A}$ medium were isolated. Population density (CFU/g tissue) was determined from each tissue, by direct counting of $\mathrm{R}_{2} \mathrm{~A}$ medium surface. morphotypes were classified by shape, color, size, and appearance. A total of 168 morphotypes were isolated from root, tillers, and leaf of different commercial varieties of rice. The lead resistance test was performed in vitro, to do that, suspensions of endophytic bacteria in log phase were prepared and inoculated in minimal medium with five concentrations of lead as $\mathrm{Pb}\left(\mathrm{NO}_{3}\right)_{2}$. The experiment was incubated at $32{ }^{\circ} \mathrm{C}$ and agitated at $150 \mathrm{rpm}$, for five days. Every hour afterstarting the test, turbidimetry measuring at $600 \mathrm{~nm}$ was conducted. Results showed the ability of endophytic bacteria to grow at concentrations of $100 \%$ of $\mathrm{Pb}$ as $\mathrm{Pb}\left(\mathrm{NO}_{3}\right)_{2}$. The results of the identification with kit API20E confirmed the presence of Burkholderia cepacia and Pseudomonas putida, which showed resistance to different lead concentrations.
\end{abstract}

Keywords: Oryza sativa, endophytic microorganisms, phytoremediation.

\footnotetext{
Recibido: 3 setiembre, 2014. Aceptado: 28 de octubre, 2014. Parte del proyecto de investigación "Implementación de un programa para la fitorremediación de ambientes contaminados con metales pesados en el Caribe Colombiano".

2 Universidad de Sucre, Facultad de Ciencias Agropecuarias, Laboratorio de Investigaciones Microbiológicas. Campus universitario Carrera 28 \# 5-267. Sincelejo (Sucre), Colombia. Teléfono: (052) 82 1240. alexander.perez@unisucre.edu.co (autor para correspondencia), saphirbr@ gmail.com, dalilamartinez23@hotmail.com
} 


\section{INTRODUCCIÓN}

La mayoría de metales pesados (por ejemplo cobre, níquel, zinc) existen naturalmente en bajas concentraciones en los suelos, rocas, agua y la biota; estas son suficientes para proveer a los sistemas vivos con nutrientes esenciales, pero en niveles altos puede causar toxicidad (Meng et al., 2013). Las altas concentraciones de metales pesados en el suelo pueden provocar cambios evolutivos, debido a sus efectos dañinos. Son potencialmente devastadores, ya que contaminan el aire, el agua y el suelo, y son utilizados por las plantas y demás eslabones de la cadena trófica (Sinhal et al., 2010).

El plomo $(\mathrm{Pb})$ es un metal que se encuentra de forma natural en el ambiente, pero las actividades antropogénicas han contribuido significativamente que incrementan sus niveles en algunos ambientes. Actividades como la minería del $\mathrm{Pb}$, los procesos industriales que utilizan el $\mathrm{Pb}$ como materia prima, la combustión de carbón y del petróleo entre otros procesos, contribuyen a la liberación de este metal en el medio ambiente (Schwarz et al., 2012). El Pb es un metal persistente en el ambiente donde es depositado y retenido (Dauvin, 2008; Flora et al., 2008); cuando se acumulan en los suelos, especialmente en los urbanos, crean problemas de salud pública y ambientales (Wong et al., 2006; Mielke et al., 2007, 2011). Más del 90\% de la contaminación ambiental producida por este metal, se debe a su capacidad de retención en las partículas de suelo y alrededor del $9 \%$ alcanza sedimentos acuáticos. La contaminación de un suelo con $\mathrm{Pb}$ es de preocupación, debido al alto tiempo de residencia en el mismos, estableciendo contacto con la hidrosfera, atmósfera y biosfera y así, contaminando ecosistemas y cadenas tróficas y alimenticias que finalmente llegan hasta los humanos (Banat, et al., 2005).

Estudios confirman que el $\mathrm{Pb}$ ocasiona problemas sanitarios y de contaminación a nivel mundial (Needleman, 2004). En los últimos años, se han adoptado medidas contra el uso del $\mathrm{Pb}$; sin embargo, su persistencia en el aire, suelo, agua y alimentos, sigue considerándose un factor de riesgo, en especial para los niños (Needleman, 2004). En el suelo se encuentra principalmente en forma de $\mathrm{Pb}^{2+}$, el cual forma compuestos insolubles tales como: $\mathrm{Pb}(\mathrm{OH})_{2}$, $\mathrm{PbCO}_{3}, \mathrm{PbS}, \mathrm{PbSO}_{4}$ (Guitart y Vernon, 2005).
Ambientes contaminados con $\mathrm{Pb}$ crean un ambiente desfavorable para el crecimiento y sobrevivencia de comunidades de microorganismos, debido a que este metal causa daño en el ADN genómico, en lípidos y proteínas, y además reemplaza iones metales esenciales como $\mathrm{Zn}, \mathrm{Ca}$ y $\mathrm{Fe}$ presentes en las proteínas. Se ha demostrado que pocos microorganismos en la naturaleza, incluyendo las bacterias, desarrollan mecanismos de protección para sobrevivir a altas concentraciones de $\mathrm{Pb}$, y así evitar que cause daño en su crecimiento y metabolismo. Literaturas especializadas señalan que los microorganismos utilizan diferentes mecanismos para resistir a altas concentraciones de $\mathrm{Pb}$, entre los que se encuentran: el eflujo, secuestro extracelular, precipitación, biosorción, bioacumulación intracelular, alteración de la morfología celular e incremento en la producción de sideróforos (Naik y Dubey, 2013).

El desarrollo de estrategias de remediación para los suelos contaminados con plomo es urgente para la conservación del medio ambiente y la salud humana (Abou-Shanab et al., 2006). Una de estas estrategias es el uso de especies fitorremediadoras para limpiar suelos contaminados con metales pesados; esta técnica en los últimos años, ha venido reemplazando a tecnologías convencionales por su rentabilidad y ser amigable con el medio ambiente (Haque et al., 2008; Chehregani et al., 2009; Kotrba et al., 2009). Sin embargo, la mayoría de las plantas fitorremediadoras identificadas hasta el momento, no son adecuadas para remediar en campo, debido a su lento crecimiento y baja producción de biomasa (Xiao et al., 2010).

Recientemente, se han comprobado los beneficios combinados de las bacterias endófitas resistentes a los metales pesados asociadas con especies de plantas, un ejemplo es la capacidad de eliminación de metales pesados tóxicos en suelos contaminados (Sheng et al., 2008). Las bacterias endófitas son aquellos microorganismos no patógenos, presentes en el interior de los tejidos de plantas sanas; estas se encuentran asociadas con la mayoría de especies de plantas monocotiledóneas y dicotiledóneas, las cuales promueven el crecimiento de las plantas (Tsavkelova et al., 2007) y aumentan la resistencia a patógenos (Aliye et al., 2008), a sequía, salinidad e incluso a herbívoros. Varios estudios sugieren que las bacterias endófitas están equipadas con mecanismos para el secuestro de metal lo que disminuye la fitotoxicidad 
de los contaminantes y la disponibilidad de los metales pesados mediante la producción de sideróforos y ácidos orgánicos (Barac et al., 2004; Taghavi et al., 2005; Sheng et al., 2008; Weyens et al., 2010).

Los efectos benéficos de las bacterias endófitas sobre las plantas bioacumuladoras son similares a los efectos que proporcionan las rizobacterias promotoras de crecimiento a las plantas, como la producción de ácido índol acético, solubilización de fosfatos, actividad de la enzima ACC desaminasa (Yan et al., 2011) y la fijación de nitrógeno (Shin et al., 2012).

Las bacterias endófitas emplean diferentes mecanismos de protección celular para adaptarse a los ambientes contaminados con altas concentraciones de plomo; entre estos se encuentran: el eflujo, secuestración extracelular, absorción en superficies celulares y en espacios intercelulares, precipitación, alteración de la morfología celular, incremento en la producción de sideróforos y la bioacumulación intracelular, entre otros (Naik y Dubey, 2013).

La acumulación de plomo metal depende de la variedad cultivada y del tipo de tejido (Cheng et al., 2006; Liu et al., 2013). Cultivos agrícolas establecidos en suelos altamente contaminados con $\mathrm{Pb}$, deben ser eliminados para evitar riesgos de exposición a los humanos. Las pasturas expuestas a concentraciones de $\mathrm{Pb}$ no se recomienda su utilización en la alimentación animal por los riesgos tóxicos y de acumulación en diferentes tejidos que esto traería (Urzelai et al., 2003; Labare et al., 2004; Migliorini et al., 2004; Darling y Thomas, 2005).

Según el Ministerio de Agricultura y Desarrollo Rural y el Instituto Interamericano de Cooperación para la Agricultura (MADR e IICA, 2005), en Colombia, el arroz es el tercer producto agrícola en extensión después del café y el maíz, representando el 13\% del área cosechada del país. Su producción representa el $11 \%$ del volumen de la producción agrícola nacional y en términos de valor, representa el 7,68\% de la actividad agrícola y el 3,9\% del total agropecuario. Como consecuencia de lo anterior, existe la necesidad de contribuir a la reducción del $\mathrm{Pb}$ en el ambiente y de esta manera, disminuir la exposición de los humanos a este metal, y así evitar el efecto tóxico que pueda ocasionar en la salud. El objetivo de este estudio fue evaluar in vitro la resistencia de bacterias endófitas a diferentes concentraciones de plomo.

\section{MATERIALES Y MÉTODOS}

\section{Área de muestreo}

Este estudio se llevó a cabo durante el primer semestre de 2013, se muestrearon plantas de variedades comerciales de arroz cultivadas en la Estación Experimental La Victoria del Fondo Nacional del Arroz, ubicado en el municipio de Montería, Córdoba, Colombia, localizado a $8^{\circ} 47^{\prime} 25^{\prime \prime}$ de longitud norte, $75^{\circ} 51^{\prime} 38^{\prime \prime}$ de longitud oeste con respecto al Meridiano de Greenwich, con una temperatura promedio de 29 ${ }^{\circ} \mathrm{C}$, humedad relativa de $80 \%$, precipitación anual promedio de $1200 \mathrm{~mm}$ y altura de $20 \mathrm{msnm}$.

La zona objeto del presente estudio estuvo ubicada al margen de la carretera principal que comunica a los departamentos del caribe colombiano con el resto de ciudades de Colombia, la cual se encuentra expuesta permanentemente a la liberación de monóxido de carbono de los vehículos que transitan diariamente. En la granja experimental la Victoria del Fondo Nacional del Arroz, este cultivo se regó con agua proveniente del Río Sinú que nace en el Nudo del Paramillo, en el departamento de Antioquia, y desemboca en Boca de Tinajones, continua a la bahía de Cispatá en el mar Caribe colombiano.

\section{Muestreo}

El muestreo se realizó aleatoriamente en forma de zig-zag colectando en cada sitio diez plantas completas (incluyendo raíces, macollas y hojas) de las variedades de arroz: Fedearroz 2000 (F2000), Fedearroz 473 (F473), Fedearroz Mocarí (Fmocarí) y Fedearroz 733 (F733), establecidas en la granja experimental en el momento del muestreo. Las muestras fueron identificadas con la variedad respectiva y fecha de colecta. Estas fueron almacenadas y conservadas para su transporte al Laboratorio de Investigaciones Microbiológicas de la Universidad de Sucre y procesadas dentro de las veinticuatro horas después de colectadas, de acuerdo con lo establecido por Pérez et al. (2013).

\section{Aislamiento de bacterias de plantas de arroz}

Las plantas colectadas de cada variedad de arroz fueron sometidas a un proceso de desinfección 
superficial. Raíces, macollas y hojas de cada planta fueron lavadas con agua estéril y cortadas en segmentos de un $1 \mathrm{~cm}$ aproximadamente. El proceso de desinfección superficial para cada tejido fue realizado de acuerdo con la metodología recomendada por Pérez et al. (2010). Después del proceso de desinfección, se procedió al aislamiento de bacterias endófitas utilizando el protocolo propuesto por Pérez et al. (2010), a saber: cada tejido desinfectado superficialmente fue depositado en un plato de porcelana, se maceró con nitrógeno líquido hasta formar una muestra homogénea. De cada una se preparó diluciones seriadas de las cuales se tomaron alícuotas y se depositaron sobre la superficie del medio agar $\mathrm{R}_{2} \mathrm{~A}$ inespecífico para el conteo de bacterias totales, y se incubaron a $28{ }^{\circ} \mathrm{C}$ por 72 horas. La densidad poblacional de bacterias por tejido (UFC/g de tejido) fue determinada mediante el conteo directo de colonias sobre la superficie de las placas. Durante el conteo se observaron y seleccionaron aquellas colonias que se diferenciaban en cuanto a forma, aspecto de la superficie, color y tamaño.

\section{Evaluación in vitro de resistencia a plomo}

La evaluación in vitro de la resistencia de bacterias endófitas a diferentes concentraciones del ion metal se realizó en medio mínimo tris-MMT (Rathnayake et al., 2013) preparado con cinco concentraciones de plomo en la forma de $\mathrm{Pb}\left(\mathrm{NO}_{3}\right)_{2}$. La concentración inicial de $\mathrm{Pb}$ utilizada en el presente estudio fue de $0,01 \mathrm{mg} / \mathrm{ml}$ $\mathrm{y}$ a partir de estas se prepararon concentraciones de 10 $(0,001 \mathrm{mg} / \mathrm{ml}), 25(0,0025 \mathrm{mg} / \mathrm{ml}), 50(0,0050 \mathrm{mg} / \mathrm{ml}$, $75(0,0075 \mathrm{mg} / \mathrm{ml})$ y $100 \%(0,01 \mathrm{mg} / \mathrm{ml})$. Alícuotas de suspensiones de bacterias endófitas en fase logarítmica fueron inoculadas sobre el medio MMT. Como control se utilizó medio MMT sin $\mathrm{Pb}\left(\mathrm{NO}_{3}\right)_{2}$. El experimento se realizó por triplicado, el cual se incubó en agitación a $150 \mathrm{rpm}$ a $32{ }^{\circ} \mathrm{C}$ por 120 horas (Zhang, et al., 2011). El crecimiento de las bacterias endófitas fue determinado mediante turbidimetría a $600 \mathrm{~nm}$ cada hora por cuatro días.

Evaluación cualitativa de la promoción de crecimiento de bacterias endófitas resistentes a $\mathbf{P b}$

Los aislados que mostraron resistencia $\mathrm{a} \mathrm{Pb}$ fueron utilizados para evaluar cualitativamente in vitro la capacidad de fijación biológica de nitrógeno y solubilizadora de fosfatos. La evaluación cualitativa de la fijación biológica de los aislamientos se realizó por la metodología propuesta por Pérez et al. (2014) en medio selectivo agar ASHBY. Cada uno de los morfotipos de aislamientos fueron sembrados en forma directa sobre la superficie del medio e incubados a $28{ }^{\circ} \mathrm{C}$ por 72 horas. Después de este tiempo, se seleccionaron los morfotipos que fueron capaces de crecer en el medio, indicando la presencia de aquellas bacterias endófitas que poseen el sistema enzimático que les permite reducir el nitrógeno atmosférico y utilizarlo en su metabolismo.

Para la evaluación cualitativa de la solubilización de fosfato de los aislamientos, se realizó, siguiendo la metodología propuesta por Pérez et al. (2014), sobre medio NBRIP con $\mathrm{Ca}_{3} \mathrm{PO}_{4}$ como fuente de fósforo insoluble a $\mathrm{pH}$ 7. Cada morfotipo fue inoculado sobre la superficie del medio e incubado a $28{ }^{\circ} \mathrm{C}$ por 72 horas. La observación cualitativa de los aislados se determinó por observación de la formación de halo transparente visible alrededor y debajo de la colonia.

\section{Identificación de las bacterias endófitas}

Para la identificación de aislados de bacterias endófitas con actividad positiva para la fijación biológica de nitrógeno y solubilización de fosfato, se utilizó el sistema de galerías API20E. La identificación se realizó mediante el sistema de códigos en software específico que identifica la bacteria mediante un banco de datos (BioMerieux, St Louis, MO, USA).

\section{Análisis estadístico}

El análisis de varianza se realizó por ANOVA multifactorial para determinar las diferencias entre densidad poblacional (UFC/g de tejido) de bacterias endófitas en función a variedad y tipo de tejido. Se utilizó la prueba múltiple de rango (Tukey) para determinar si hubo diferencias entre las densidades poblacionales de bacterias endófitas (UFC/g de tejidos) aisladas.

\section{RESULTADOS Y DISCUSIÓN}

\section{Aislamiento de bacterias endófitas cultivables}

Un total de 168 morfotipos de bacterias endófitas fueron aislados de las variedades comerciales de 
arroz: F2000, F473, Fmocarí y F733. El análisis de varianza mostró diferencias altamente significativas de la densidad poblacional en función a tipo de tejido y variedad de arroz analizada. La prueba múltiple de rangos de acuerdo con la media estándar de cada tejido y variedad analizada, mostró que la mayor densidad poblacional se observó en la raíz $(3,045$ x $10^{10} \mathrm{UFC} / \mathrm{g}$ de tejido) con respecto a macolla $(4,35$ $\left.\mathrm{x} 10^{9}\right)$ y hoja $\left(7,34 \times 10^{8} \mathrm{UFC} / \mathrm{g}\right.$ de tejido) (Figura 1). Así mismo, se evidenció alta densidad de estas bacterias en las variedades F733 $\left(2,12 \times 10^{10} \mathrm{UFC} / \mathrm{g}\right.$ de tejido) y Fmocarí $\left(2,09 \times 10^{10} \mathrm{UFC} / \mathrm{g}\right.$ de tejido $)$ y bajas poblaciones en F2000 (1,56 x $10^{7} \mathrm{UFC} / \mathrm{g}$ de tejido) y F473 (2,07 x $10^{7} \mathrm{UFC} / \mathrm{g}$ de tejido).

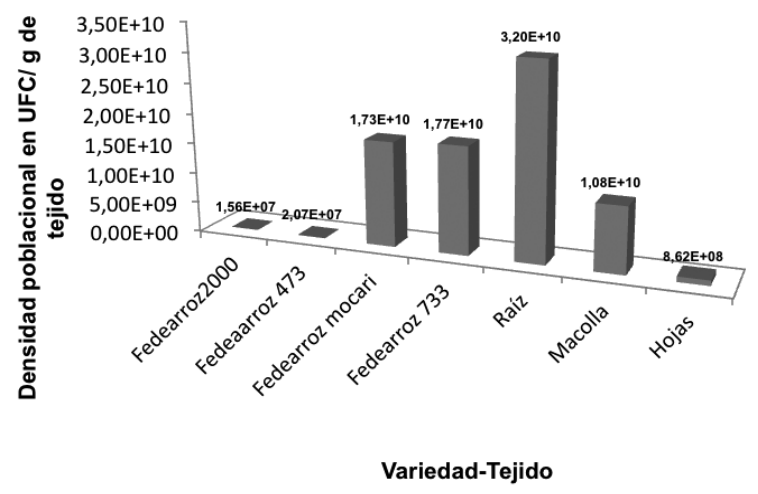

Figura 1. Resultados de prueba múltiple de rangos aplicados a la densidad poblacional (UFC/g) de bacterias endófitas en función de la variedad de arroz colectada y tipo de tejido analizado. Departamento de Córdoba, Colombia. Primer periodo de 2013.

Figure 1. Results of multiple range tests applied to population density (CFU/g) of endophytic bacteria, depending on the variety of rice collected and the type of tissue evaluated. Córdoba, Colombia, first half of 2013.

Estudios comparativos sobre densidad poblacional de bacterias endófitas asociadas a las mismas variedades de arroz, realizadas en la granja experimental La Victoria en el segundo semestre de 2012, con el propósito de evaluar la densidad poblacional de bacterias endófitas con respecto a la etapa de floración, revelaron mayores densidades de bacterias endófitas en raíces $3,2 \times 10^{10} \mathrm{UFC} / \mathrm{g}$ de tejido, con respecto a tallo, hojas, hoja bandera y panícula; asimismo, se identificó a las variedades F733 $\left(1,77 \times 10^{10} \mathrm{UFC} / \mathrm{g}\right.$ de tejido $)$ y Fmocarí $\left(1,7 \times 10^{10}\right.$ UFC/g de tejido) con la mayor densidad poblacional, con respecto a las variedades F273 y F2000, con densidades de $2,0 \times 10^{7}$ y $1,56 \times 10^{7} \mathrm{UFC} / \mathrm{g}$ de tejido, respectivamente (Pérez et al., 2013).

Los resultados obtenidos en el presente estudio, cuando las variedades analizadas se encontraban en etapa de macollamiento, señalan que los valores de densidad de bacterias endófitas encontrados, fueron menores a los reportados por Pérez et al. (2013). La densidad poblacional de bacterias endófitas fue variable y se vio afectada por diversos factores como: época del año, el tipo de tejido, especie, variedad de plantas (Mocali et al., 2003) y la interacción de las bacterias endófitas con otros microorganismos benéficos (Araujo et al., 2002).

\section{Resistencia de bacterias endófitas a plomo}

Los resultados mostraron que solo dos morfotipos del total evaluado (168), crecieron sobre las diferentes concentraciones de plomo utilizadas. Los morfotipos que mostraron resistencia a $\mathrm{Pb}$ corresponden a: $\mathrm{M}_{1} \mathrm{~T}_{\mathrm{Fm}}$ (M: morfotipo, 1:morfotipouno, T: tallo, Fm), $\mathrm{M}_{2} \mathrm{~T}_{\mathrm{F} 733}$ (M: mofotipo, 2: morfotipodos, T: tallo, F733).

Para los morfotipos $\mathrm{M}_{1} \mathrm{~T}_{\mathrm{Fm}}$ y $\mathrm{M}_{2} \mathrm{~T}_{\mathrm{F} 733}$ se encontraron diferencias significativas entre las medias de cada tratamiento (p: 0,0005 y p: 0,0136). La prueba múltiple de rango mostró que estos morfotipos presentaron mayor crecimiento en $\mathrm{Pb}\left(\mathrm{NO}_{3}\right)_{2}$ a concentraciones de $10,25,50$ y $75 \%$ con respecto al tratamiento $100 \%$, y tomando como referencia el crecimiento del testigo utilizado (Figura 2).

Asimismo, el morfotipo $\mathrm{M}_{2} \mathrm{~T}_{\mathrm{F} 733}$ mostró menor crecimiento en las diferentes concentraciones de $\mathrm{Pb}$, comparado con los valores obtenidos para la bacteria endófita $\mathrm{M}_{1} \mathrm{~T}_{\mathrm{Fm}}$. Las diferencias observadas en el crecimiento de los morfotipos en diversas concentraciones de $\mathrm{Pb}$, posiblemente pueden ser atribuidas a la variación en la densidad poblacional de cada morfotipo como a la estrategia tanto metabólica como molecular, utilizada por cada uno de ellos. Sin embargo, la interacción entre el metal y la bacteria puede ser un mecanismo clave que contribuye a la biodisponibilidad y toxicidad del metal (KamalaKannan y Krishnamoorthy, 2006). Estudios posteriores determinarán que factores ecológicos in vitro pueden 


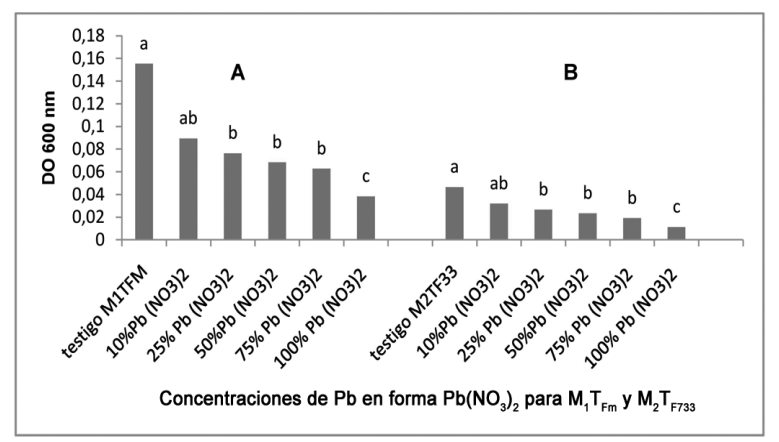

Figura 2. Resultados obtenidos de la prueba múltiple de rangos aplicados en forma individual a cada morfotipo: A: $\mathrm{M}_{1} \mathrm{~T}_{\mathrm{Fm}}$ (M1: morfotipo1, $\mathrm{T}$ : tallo, Fm: Fmocari) y B: $\mathrm{M}_{2} \mathrm{~T}_{\mathrm{F} 733}$ (M2: morfotipo2, $\mathrm{T}$ : tallo, F733) de bacteria endófitas evaluados in vitro en función de diferentes concentraciones de $\mathrm{Pb}$ utilizada. Laboratorio de Investigaciones Microbiológicas, Universidad de Sucre, SincelejoSucre, Colombia. 2013.

Diferencias significativas a $\mathrm{p}<0.05$. Letras iguales no hay diferencias significativas entre concentración de $\mathrm{Pb}$.

Figure 2. Results of multiple ranges test applied individually to each morphotype testing $\mathrm{A}: \mathrm{M}_{1} \mathrm{~T}_{\mathrm{Fm}}$ (M1: morfotipo1, T: tallo, Fm: Fmocari ) and B: $\mathrm{M}_{2} \mathrm{~T}_{\mathrm{F7} 33}$ (M2: morfotipo2, T: tallo, F733) of endophytic bacteria evaluated in vitro according to the different $\mathrm{Pb}$ concentrations used. Microbiology Research Laboratory at the University of Sucre, Sincelejo-Sucre, Colombia. 2013.

Significant differences at $\mathrm{p}<0.05$. Equal letters there are no significant differences among concentration of $\mathrm{Pb}$.

influir en el crecimiento y resistencia de bacterias endófitas a diferentes concentraciones de $\mathrm{Pb}$.

Un comportamiento de crecimiento variado en los diferentes tratamientos, siendo el tratamiento con una concentración de $10 \% \mathrm{~Pb}\left(\mathrm{NO}_{3}\right)_{2}$ el que mostró una mayor densidad óptica $\left(\mathrm{OD}_{600 \mathrm{~nm}}\right)$ hasta las $15 \mathrm{~h}$, seguido de los tratamientos con $25,50,75 \% \mathrm{~Pb}\left(\mathrm{NO}_{3}\right)_{2}$, respectivamente (Figura 3).

Con respecto al morfotipo $\mathrm{M}_{2} \mathrm{~T}_{\mathrm{F} 733}$ (Figura 4), se observó que presentó menor crecimiento en los diferentes tratamientos con respecto a los mostrados por el morfotipo $\mathrm{M}_{1} \mathrm{~T}_{\mathrm{Fm}}$ (Figura 3).

Los resultados obtenidos de la prueba in vitro de resistencia a $\mathrm{Pb}$, mediante la curva de crecimiento, mostraron que el morfotipo $\mathrm{M}_{2} \mathrm{~T}_{\mathrm{F} 733}$ tuvo un comportamiento similar de crecimiento al $\mathrm{M}_{1} \mathrm{~T}_{\mathrm{Fm}}$ y al igual que en este, se apreció una fase de adaptación tardía con respecto al testigo (Figura 4). Los resultados de la curva de crecimiento mostraron que cuando este morfotipo fue sometido en crecimiento con tratamiento de $10 \%$ de $\mathrm{Pb}\left(\mathrm{NO}_{3}\right)_{2}$, se presentó el mayor crecimiento con respecto a los demás tratamientos con 25,50 y $75 \%$ de $\mathrm{Pb}\left(\mathrm{NO}_{3}\right)_{2}$.

Los resultados obtenidos en el presente experimento señalan que las bacterias endófitas aisladas de variedades comerciales de arroz, mostraron comportamientos de crecimiento variados. Por no existir literatura especializada de resistencia de bacterias endófitas a $\mathrm{Pb}$ aisladas de variedades comerciales de arroz, se consideran estos resultados como preliminares; sin embargo, estudios posteriores permitirán determinar la concentración mínima inhibitoria de $\mathrm{Pb}$ sobre el crecimiento de estas bacterias, así como establecer la relación de concentración de $\mathrm{Pb}$ en tejidos de variedades de arroz y densidad poblacional de bacterias endófitas, y la determinación de otros factores ambientales implicados directamente en la resistencia de $\mathrm{Pb}$ por parte de las bacterias endófitas.

Los estudios llevados a cabo sobre resistencia de bacterias endófitas a altas concentraciones de plomo, señalan que algunas especies de microorganismos, incluyendo a las bacterias, emplean una variedad de mecanismos de protección para sobrevivir a altos niveles de plomo sin ocasionar ningún tipo de efecto sobre su crecimiento y el metabolismo.

\section{Identificación de bacterias endófitas}

Los resultados obtenidos de la identificación de los aislados de bacterias endófitas resistentes a $\mathrm{Pb}\left(\mathrm{NO}_{3}\right)_{2}$ confirmaron que los morfotipos analizados mostraron similitud con las especies almacenas en el banco de datos de BioMerieux, St Louis, MO, USA, con Pseudomonas putida $\left(\mathrm{M}_{1} \mathrm{~T}_{\mathrm{Fm}}\right)$ y Burkholderia cepacia $\left(\mathrm{M}_{2} \mathrm{~T}_{\mathrm{F} 733}\right)$. Los resultados encontrados no mostrados indican que estos morfotipos poseen capacidad para fijar nitrógeno y/o solubilizar fosfatos. El morfotipo identificado como Pseudomonas putida solubilizó cualitativamente fosfatos. Entre tanto, el morfotipo relacionado con Burkholderia cepacia mostró capacidad de solubilización de fosfato y de fijar nitrógeno.

Se dificultó la comparación de los resultados obtenidos de la evaluación de resistencia de bacterias endófitas a diferentes concentraciones de plomos por 


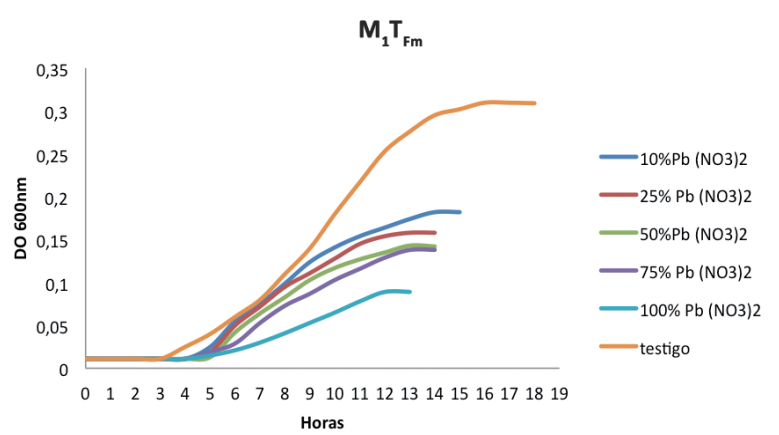

Figura 3. Resultado de la curva de crecimiento del morfotipo $\left(\mathrm{M}_{1} \mathrm{~T}_{\mathrm{Fm}}\right)$, a diferentes concentraciones de plomo en forma de $\mathrm{Pb}\left(\mathrm{NO}_{3}\right)_{2}$. $\mathrm{M}_{1}$ : morfotipo 1, T: tallo, Fm: Fmocari. Laboratorio de Investigaciones Microbiológicas, Universidad de Sucre, SincelejoSucre, Colombia. 2013.

Figure 3. Result of morphotype $\left(\mathrm{M}_{1} \mathrm{~T}_{\mathrm{Fm}}\right)$ growth curve to different concentrations of lead as $\mathrm{Pb}\left(\mathrm{NO}_{3}\right)_{2}$. M1: morphotype one; T: stem; Fm: Fmocari. Microbiology Research Laboratory at the University of Sucre, Sincelejo-Sucre, Colombia. 2013.

no estar disponible literatura sobre investigaciones similares; sin embargo, otros estudios in vitro sobre resistencia de bacterias endófitas a $\mathrm{Pb}$ y a otros metales pesados como cadmio (Cd) mostraron que especies de bacterias del grupo de Burkholderia sp. poseen la capacidad de solubilizar in vitro metales como $\mathrm{Pb}$ y $\mathrm{Cd}$ en diferentes concentraciones y de acumular estos dos metales en tejidos de plantas de maíz y tomate, y la subsecuente estimulación del crecimiento de estas plantas in vivo (Chun-yu et al., 2008).

$P$. putida ha sido reportada como una bacteria endófita asociada a la rizosfera de cultivos de arroz (Hardoim et al., 2011) y de papa (Andreote et al., 2009). P. putida constituye un amplio grupo de bacterias muy diversas presentes en multitud de entornos del suelo, y en ocasiones también se le puede encontrar viviendo en la rizosfera de plantas, en una relación simbiótica; además, se caracteriza por su amplia versatilidad metabólica y su plasticidad genética. Estas bacterias son capaces de asimilar una gran variedad de nutrientes, entre ellos solventes orgánicos y compuestos tóxicos de diverso origen. La ubicuidad de la especie $P$. putida refleja una capacidad para adaptarse a ambientes contaminados o sin contaminar, con condiciones fisicoquímicas diferentes y en continuo cambio; esta bacteria tiene

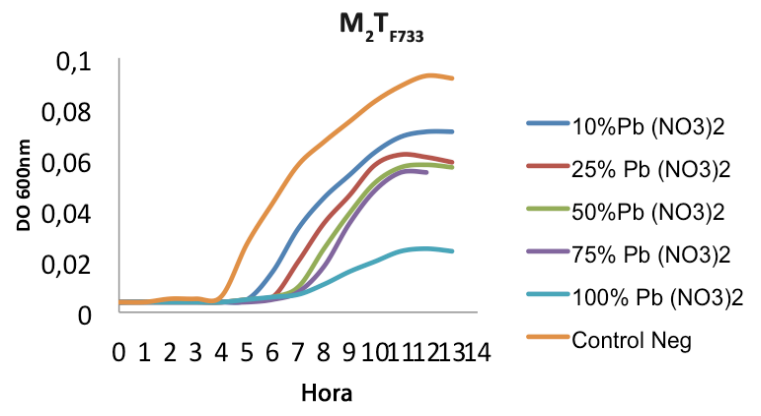

Figura 4. Resultado de la curva de crecimiento del morfotipo $\left(\mathrm{M}_{2} \mathrm{~T}_{\mathrm{F} 733}\right)$ a diferentes concentraciones de plomo como $\mathrm{Pb}\left(\mathrm{NO}_{3}\right)_{2}$. $\mathrm{M}_{2}$ : morfotipo 2, T: tallo, F733: variedad F733. Laboratorio de Investigaciones Microbiológicas, Universidad de Sucre, Sincelejo-Sucre, Colombia. 2013.

Figure 4. Result of morphotype $\left(\mathrm{M}_{2} \mathrm{~T}_{\mathrm{F} 733}\right)$ growth curve to different concentrations of lead in the form of $\mathrm{Pb}\left(\mathrm{NO}_{3}\right)_{2} . \mathrm{M}_{2}$ : morphotype two; T: stem; F733: variety F733. Microbiology Research Laboratory at the University of Sucre, Sincelejo- Sucre, Colombia. 2013.

además la capacidad de usar aminoácidos como fuente de carbón y nitrógeno (Nigam et al., 2012).

El género de bacteria Burkholderia representa a un grupo de dieciocho especies relacionadas que actualmente tienen interés por la extraordinaria versatilidad como patógenos de plantas, saprofitos, agentes de biocontrol, biorremediación y patógeno de humanos. Estas bacterias abundan naturalmente en el suelo, agua y en la superficie de distintas especies vegetales, poseen capacidad de metabolizar un amplio rango de compuestos orgánicos como fuente de carbono y energía. Una cualidad que ha despertado interés en este grupo de bacterias es su uso en biorremediación de suelos y agua subterránea contaminadas con hidrocarburos y herbicidas (Orelio et al., 2014).

Comparando estudios realizados con bacterias endófitas resistentes a $\mathrm{Pb}$ y $\mathrm{Zn}$ y aisladas de especie Commelina (Zhang et al., 2011), reportaron un total de 49 filotipos con capacidad para resistir a diferentes concentraciones de plomo y que producen la enzima ACC desaminasa, el compuesto ácido indol-3-acético (AIA) y sideróforos. La presencia de estos compuestos obtenidos, posiblemente estimularon el crecimiento de las plantas y ayudaron a la absorción de $\mathrm{Pb}$ en dicha especie vegetal. 
Otros estudios realizados con la especie de bacteria endófita identificada como Bacillus sp. MN34 , comprobaron su capacidad de resistir a diferentes concentraciones de plomo y su capacidad de acumular este metal en tejidos de la especie vegetal Alnus firma. Los resultados obtenidos in vitro con esta especie de bacteria; mostraron que más del $95 \%$ de los iones de plomo fueron removidos a $\mathrm{pH}$ 9:0 y el 73\% a pH 7:0. Sin embargo, cambios drásticos en la tasa de remoción de este metal fue observado a $\mathrm{pH}$ 4:0, la diferencia de remoción puede ser atribuida parcialmente a la variación en la densidad poblacional (Shin et al., 2012). Estudios llevados a cabo por Sheng et al. (2008), demostraron que las especies de bacterias endófitas Pseudomonas fluorescens G10 y Mycobacterium sp G16, in vitro tuvieron la capacidad de reducir la toxicidad de plomo en la especie vegetal Brassica napus. Estudios mostraron que los efectos benéficos de las bacterias endófitas asociadas a especies de plantas hiperacumuladoras de metal pesado, fueron similares a los que producen las rizobacterias promotoras de crecimiento, los cuales incluyen la producción de ácido índol acético, solubilización de fosfatos, producción, actividad de la enzima ACC desaminasa y la fijación de nitrógeno (Sheng et al., 2008; Shin et al., 2012).

A pesar de existir reportes de estudios en literaturas especializadas que señalan la importancia de inoculación de bacterias endófitas para promover el crecimiento vegetal y la remoción de metales pesados en ambientes contaminados, a la fecha del presente estudio no existían reportes sobre $P$. putida y $B$. cepacia como bacterias endófitas resistentes a $\mathrm{Pb}$. Estas bacterias endófitas se considera que podrían convertirse en posibles recursos biológicos para ser utilizadas para mejorar el crecimiento en cultivo de arroz y consecuentemente incrementar la toma y resistencia de $\mathrm{Pb}$ en estas variedades.

\section{AGRADECIMIENTO}

Los autores agradecen al Laboratorio de Investigaciones Microbiológicas de la Universidad de Sucre y al equipo de investigadores vinculados a él.

\section{LITERATURA CITADA}

Abou-Shanab, R.A.I., J.S. Angle, and R.L. Chaney. 2006. Bacterial inoculants affecting nickel uptake by Alyssum murale from low, moderate and high Ni soils, Soil Biol. Biochem. 38:2882-2889.

Andreote, F.D., W.L. Araujo, J.L. Azevedo, E.J. Van, U. Nunes, and O.L. Van. 2009. Endophytic colonization of potato (Solanum tuberosum L.) by a novel competent bacterial endophytic, Pseudomonas putida strain $\mathrm{P}_{9}$, and its effect on associated bacterial communities. Appl. Environ. Microbiol. 75:3396-3406.

Aliye, N., Fininsa, C., and Y. Hiskias. 2008. Evaluation of rhizosphere bacterial antagonists for their potential to bioprotect potato (Solanum tuberosum) against bacterial wilt (Ralstonia solanacearum). Biol. Control 47:282-288

Araujo, W. L., J. Marcon, W.J. Maccheroni, E.J. Van, J.W. Van, and J.L. Azevedo. 2002. Diversity of endophytic bacterial populations and their interaction with Xylella fastidiosa in citrus plants. Appl. Environ. Microbiol. 68:4906-4914.

Banat, K.M., F. Howari, and A.A. Al-Hamad. 2005. Heavy metals in urban soils of Central Jordan: should we worry about their environmental risks. Environ. Res. 97:258-273

Barac, T.S., B. Taghavi, A. Borremans, L. Provoost, J.V. Oeyen, J. Colpaert, D. Vangronsveld, and L. Van der. 2004. Engineered endophytic bacteria improve phytoremediation of water-soluble, volatile, organic pollutants. Nat. Biotechnol. 22:583-588.

Chehregani, A., M. Noori, and H.L. Yazdi. 2009. Phytoremediation of heavy-metal-polluted soils: Screening for new accumulator plants in Angouran mine (Iran) and evaluation of removal ability. Ecotoxicol. Environ. Safe. 72:1349-1353.

Cheng, F., N. Zhao, H. Xu, Y. Li, W. Zhang, and Z. Zhu. 2006. Cadmium and lead contamination in japonica rice grains and its variation among the different locations in southeast China. Sci. Total Environ. 359:156-66.

Chun-Yu, J., S. Xia-fang, Q. Meng, and W. Qing-Ya. 2008. Isolation and characterization of a heavy metal-resistant Burkholderia sp. from heavy metalcontaminated paddy field soil and its potential in promoting plant growth and heavy metal accumulation in metal-polluted soil. Chemosphere 72(2):57-64. 
Darling, C.T.R., and V.G. Thomas. 2005. Lead bioaccumulation in earthworms, Lumbricus terrestris, from exposure to lead compounds of differing solubility. Sci. Total Environ. 346:70-80.

Dauvin, J.C. 2008. Effects of heavy metal contamination on the macrobenthic fauna in estuaries: the case of the Seine estuary. Mar. Pollut. Bull. 57:160-167.

Flora, S.J.S., M. Mittal, and A. Mehta. 2008. Heavy metal induced oxidative stress and its possible reversal by chelation therapy. Indian J. Med. Res. 128:501-523.

Guitart, R., y T. Vernon. 2005. Es el plomo empleado en deportes (caza, tiro y pesca deportiva) un problema de salud pública infravalorado?. Rev. Esp. Salud Pública 79:621-632.

Haque, N., J.R. Peralta-Videa, G.L. Jones, T.E. Gill, and J.L. Gardea-Torresdey. 2008. Screening the phytoremediation potential of desert broom (Baccharis sarothroides Gray) growing on mine tailings in Arizona, USA, Environ. Pollut. 153:362-368.

Hardoim, P.R.,F.D.Andreote, B. Reinhold-Hurek,A. Sessitsch, O.L. Van, and E.J. Van. 2011. Rice root associated bacteria: insights into community structures across 10 cultivars. FEMS Microbiol. Ecol. 77:154-164.

Kamala-Kannan, S., and R. Krishnamoorthy. 2006. Isolation of mercury resistant bacteria and influence of abiotic factors on bioavailability of mercury - a case study in Pulicat Lake north of Chennai, south east India. Sci. Total Environ. 367:341-353.

Kotrba, P., J. Najmanova, T. Macek, T. Ruml, and M. Mackova. 2009. Genetically modified plants in phytoremediation of heavy metal and metalloid soil and sediment pollution. Biotechnol. Adv. 27:799-810.

Labare, M.P., M.A. Butkus, D. Riegner, N. Schommer, and J. Atkinson. 2004. Evaluation of lead movement from the abiotic to biotic at a small-arms firing range. Environ. Geol. 46:750-754.

Liu, J., X. Ma, M., Wang, and X. Sun. 2013. Genotypic differences among rice cultivars in lead accumulation and translocation and the relation with grain $\mathrm{Pb}$ levels. Ecotoxicol Environ Saf. 90:35-40.

MADR e IICA (Ministerio de Agricultura y Desarrollo Rural e Instituto Interamericano de Cooperación para la Agricultura). 2005. La competitividad de las cadenas productivas en Colombia. Análisis de su estructura y dinámica (1991-2004). MADR, Bogotá, COL.

Meng, Li., Ch. Xiaohui, and G. Hongxian. 2013. Heavy metal removal by biomineralization of urease producing bacteria isolated from soil. Int. Biodeterior. Biodegrad. 76:81-85.
Mielke, H.W., E.T. Powell, C.R. Gonzales, and J.P.W Mielke. 2007. Potential lead on play surfaces: evaluation of the "PLOPS" sampler as a new tool for primary lead prevention. Environment Research. 103:154-159.

Mielke, H.W., M.A.S. Laidlaw, and C.R. Gonzales. 2011. Estimation of leaded $(\mathrm{Pb})$ gasoline's continuing material and health impacts on 90 US urbanized areas. Environ. Int. 37:248-257.

Migliorini, M., G. Pigino, N. Bianchi, F. Bernini, and C. Leonzio. 2004. The effects of heavy metal contamination on the soil arthropod community of a shooting range. Environ. Pollut. 129:331-40.

Mocali, S., E. Bertelli, C. DI, A. Mengoni, A. Sfalanga, F. Viliani, A. Caciotti, and S.G. Tegli. 2003. Fluctuation of bacteria isolated from elm tissues during different seasons and from different plant organs. Res. Microbiol. 154:105-114.

Naik, M.M., and S.K. Dubey. 2013. Lead resistant bacteria: Lead resistance mechanisms, their applications in lead bioremediation and biomonitoring. Ecotoxicol. Environ. S. 98:1-7.

Needleman, H. 2004. Lead poisoning. Annu. Rev. Med. 55:209-22.

Nigam,A., S.P. Prashant, and P.W.Pramod. 2012. Assessment of the metabolic capacity and adaptability of aromatic hydrocarbon degrading strain Pseudomonas putida CSV86 in aerobic chemostat culture. Bioresour. Technol. 114:484-491.

Orelio, C.C., H.W. Beiboer, M.C. Morsink, S.Tektas, H.E. Dekter, and W.B. Van Leeuwen. 2014. Comparison of Raman spectroscopy and two molecular diagnostic methods for Burkholderia cepacia complex species identification. J. Microbiol. Methods 107:126-132.

Pérez, C. A., C.C. Pérez, y A.L. Chamorro. 2013. Diversidad de bacterias endófitas asociadas a cultivo de arroz en el departamento de Córdoba-Colombia. Estudio preliminar. Rev. Colomb. Cienc. Anim. 5(1):83-92.

Pérez, C.A., S.J. Rojas, y C.J. Fuente. 2010. Diversidad de bacterias endófitas asociadas a raíces del pasto colosuana (Bothriochloa pertusa) en tres localidades del departamento de Sucre, Colombia. Rev. Acta Biol. Colomb. 15:1-18.

Pérez, A.C., S.A. Tuberquía, y J.D. Amell. 2014. Actividad in vitro de bacterias endófitas fijadoras de nitrógeno y solubilizadoras de fosfatos. Agron. Mesoam. 25:0111 .

Rathnayake, I.V.N., M. Mallavarapu, G.S.R. Krishnamurti, N.S. Bolan, and R. Naidu R. 2013. Heavy metal toxicity to bacteria - Are the existing growth media 
accurate enough to determine heavy metal toxicity. Chemosphere 90:1195-1200.

Schwarz, K., S.T. Pickett, R.G. Lathrop, K.C. Weathers, R.V. Pouyat, and M.L. Cadenasso. 2012. The effects of the urban built environment on the spatial distribution of lead in residential soils. Environ. Pollut. 163:32-39.

Sheng, X.F., J.J. Xia, C.Y. Jiang, L.Y., He, and M. Qian. 2008. Characterization of heavy-metal resistant endophytic bacteria from rape (Brassica napus) roots and their potential in promoting the growth and lead accumulation of rape. Environ. Pollut. 156:1164-1170.

Shin, M.N., J. Shim, Y. You, H. Myung, K.S. Bang M. Cho, S.K. Kannan, and B-T Oh. 2012. Characterization of lead resistant endophytic Bacillus sp. MN3-4 and its potential for promoting lead accumulation in metal hyperaccumulator Alnus firma. J. Hazard. Mater. 199200:314-320.

Sinhal, V.K., Srivastava, A., and V.P. Singh. 2010. EDTA and citric acid mediated phytoextraction of $\mathrm{Zn}, \mathrm{Cu}, \mathrm{Pb}$ and $\mathrm{Cd}$ through marigold (Tagetes erecta). J. Environ. Biol. 31:255-259.

Taghavi, S.T., B. Barac, B. Greenberg, J. Borremans, D. Vangronsveld, and L. Van der. 2005. Horizontal gene transfer to endogenous endophytic bacteria from poplar improves phytoremediation of toluene. Appl. Environ. Microbiol. 71:8500-8505.

Tsavkelova, E.A., T.A. Cherdyntseva, S.G. Botina, and A.L. Netrusov. 2007. Bacteria associated with orchid roots and microbial production of auxin. Microbiol Res. 162(1):69-76.
Urzelai, A., E. Ciprián, A. Roldán, E. Cagigal, and A. Bonilla. 2003. Environmental impact and risk associated to clay target shooting ranges. Proceedings of the $8^{\text {th }}$ International FZK/TNO Conference on Contaminated Soil. Gent, BEL.

Weyens, N.S., J. Croes, L.N.D. Dupae, L.R. Van der and J.V. Carleer. 2010. Endophytic bacteria improve phytoremediation of $\mathrm{Ni}$ and TCE co-contamination. Environ. Pollut. 158:2422-2427.

Wong, C.S.C., X. Li, and I. Thornton. 2006. Urban environmental geochemistry of trace metals. Environ. Pollut. 142(1):1-16.

Xiao, X., S.L. Luo, G.M. Zeng, W.Z. Wei, Y. Wan, L. Chen, H.J. Guo, Z. Cao, L.X. Yang, J.L. Chen, and Q. Xi. 2010. Biosorption of cadmium by endophytic fungus (EF) Microsphaeropsis sp. LSE10 isolated from cadmium hyperaccumulator Solanum nigrum L., Bioresour. Technol. 101:1668-1674.

Yan, F.Z., Y.H. Lin, J.Ch. Zhao, H.Z. Wen, Y.W. Qing, Q. Meng, and F.S. Xia. 2011. Characterization of leadresistant and ACC desaminase-producing endophytic bacteria and their potential in promoting lead accumulation of rape. Hazard. Mater. 186:1720-1725.

Zhang Y.F., L.Y. He, Z.J. Chen, W.H. Zhang, Q.Y. Wang, M. Qian, and X.F. Sheng. 2011. Characterization of leadresistant and ACC deaminase-producing endophytic bacteria and their potential in promoting lead accumulation of rape. J. Hazard. Mater. 186:17201725 . 